\title{
Use of the PREPARE (PREhabilitation, Physical Activity and exeRcisE) program to improve outcomes after lumbar fusion surgery for severe low back pain: a study protocol of a person-centred randomised controlled trial
}

Hanna Lotzke ${ }^{1,2,13^{*}}$, Max Jakobsson 1,3, Helena Brisby ${ }^{1,9}$, Annelie Gutke ${ }^{4}$, Olle Hägg ${ }^{1,2}$, Rob Smeets ${ }^{5,6}$, Marlies den Hollander ${ }^{7,8}$, Lars-Eric Olsson ${ }^{10,11,12}$ and Mari Lundberg ${ }^{1,9,10}$

\begin{abstract}
Background: Following lumbar fusion surgery, a successful outcome is empirically linked to effective rehabilitation. While rehabilitation is typically postoperative, the phase before surgery - termed prehabilitation - is reportedly an ideal time to prepare the patient. There are presently no guidelines for prehabilitation before lumbar fusion surgery. Physical activity has well-known health benefits, and staying physically active despite pain is a major principle in non-pharmacological chronic low back pain treatment. Psychological factors such as fear of movement, pain catastrophizing and low self-efficacy are known to be barriers to staying active. No studies have investigated prehabilitation protocols that promote physical activity and target psychological risk factors before lumbar fusion surgery. The aim of our proposed randomised controlled trial is to investigate whether patients who undergo lumbar fusion surgery for degenerative disc disease experience better functioning with a physiotherapeutic prehabilitation program (PREPARE) based on a cognitive behavioural approach compared to conventional care.

Methods/Design: We will recruit 110 patients between 18-70 years of age with degenerative disc disease who are waiting for lumbar fusion surgery. These patients will be randomly assigned to receive either PREPARE or conventional care. PREPARE uses a person-centred perspective and focuses on promoting physical activity and targeting psychological risk factors before surgery. The primary outcome will be disability measured using the Oswestry Disability Index 2.0. Secondary outcomes will include functioning (patient-reported and performance-based), physical activity (accelerometer), health-related quality of life, back and leg pain intensity, pain catastrophizing, kinesiophobia, self-efficacy, depression, anxiety, satisfaction with treatment results and health economic factors. Data will be collected at baseline (preoperatively) after the intervention (preoperatively), 3 and 8 weeks, 3, 6, 12, 24 and 60 months postoperatively.

(Continued on next page)
\end{abstract}

* Correspondence: hanna.lotzke@gu.se

'Department of Orthopaedics, Institute of Clinical Science, Sahlgrenska

Academy, University of Gothenburg, Gothenburg, Sweden

${ }^{2}$ Spine Center Göteborg, Västra Frölunda, Sweden

Full list of author information is available at the end of the article 
(Continued from previous page)

Discussion: We hypothesise that the focus on promoting physical activity and targeting psychological risk factors before surgery will decrease disability and help the patients to be more active despite pain both before and after surgery. We will use a combination of outcome measures both patient-reported and performance-based, as well as accelerometer data. This will provide a more comprehensive picture of the patient's functioning than just patient-reported outcomes alone.

Trial registration: Current Controlled Trials ISCRTN17115599, Retrospectively Registered 18 May 2015.

Keywords: Prehabilitation, Rehabilitation, Spinal fusion surgery, Physiotherapy, Cognitive behavioural approach, Person-centred, Chronic low back pain, Physical activity

\begin{abstract}
Abbreviations: CLBP, Chronic Low Back Pain; DDD, Degenerative Disc Disease; EQ-5D, EuroQol 5 Dimensions Questionnaire; HADS, Hospital Anxiety and Depression Scale; ICER, Incremental Cost-Effectiveness Ratio; ODI, Oswestry Disability Index 2.0; PCC, Person-Centred Care; PCS, Pain Catastrophizing Scale; PSFS, Patient-Specific Functional Scale; QALY, Quality Adjusted Life Years; RCT, Randomised Controlled Trial; SEE-SV, Self-Efficacy Scale for Exercise; SF-36, Short Form (36) Health Survey; TSK, Tampa Scale for Kinesiophobia; VAS, Visual Analogue Scale
\end{abstract}

\section{Background}

Lumbar degenerative disc disease (DDD) is a subgroup of chronic low back pain (CLBP). When pain and disability are severe, lumbar fusion surgery can be an option [1]. The frequency of lumbar spinal fusion surgery is increasing worldwide [2,3]. In 2008, DDD was the most common diagnosis prior to spinal fusion surgery in the USA [4]. In 2013, the Swedish Spine Register recorded 8144 patients with degenerative lumbar spine disorders, of which approximately $10 \%$ had a primary diagnosis of DDD or isthmic spondylolisthesis and underwent lumbar fusion surgery [5]. The DDD group is an interesting study group for several reasons. They are relatively young [5], and their lack of functioning has hence a large impact on their life and on society. Clinical experience dictates that most patients choose fusion surgery to enable them to continue to work and to live an active life.

While rehabilitation traditionally starts postoperatively, the phase before surgery - termed prehabilitation - is suggested to be an ideal time to prepare patients for an optimal outcome of surgery [6,7]. A small number of studies of low-quality suggest that there is no evidence for the effectiveness of physiotherapy interventions before and after lumbar fusion, and hence best practice remains unclear [8]. We lack guidelines for the pre and post-operative phase for this patient group [9, 10], but there are national and international guidelines for conservative or non-pharmacological treatment for patients with CLBP. These guidelines incorporate major treatment principles, such as to stay active despite pain along with supervised exercise therapy, cognitive behavioural therapy and multidisciplinary treatment [11]. There is no reason to believe that patients with DDD would not benefit from the same treatment principles.

The benefits of staying or becoming more physically active are manifold. The major underlying rationale is the effect of physical activity on general health [12, 13].
On a global level physical inactivity is one of the global burdens, leading to premature death and noncommunicable diseases [13]. It is hence important to promote physical activity in all conditions, patients with CLBP alike. Patients with DDD who choose to undergo surgery have experienced pain for several years, and $52 \%$ of them reported that they are able to walk less than one kilometre [3]. However, there are presently little data regarding physical activity levels in this patient group. In addition to its general health benefits, physical activity has an analgesic effect that likely involves several partially overlapping mechanisms [14, 15]. The hypoalgesic effect of exercise on pain is usually reduced in patients with "more general" chronic pain conditions [14]. However, the exercise-induced hypoalgesic effects in patients with CLBP are reportedly similar to those in healthy individuals $[16,17]$. It would hence be of value to promote physical activity for patients with DDD.

There are various reasons for not being physically active. One factor is the perception and attitude towards exercises [18]. Another factor is fear of movement. This factor has been identified as an important mediator in combination with catastrophizing thoughts regarding disability, disuse and depression in patients with CLBP [19]. It appeared that $70 \%$ of the patients with CLBP who visited an orthopaedic department in Sweden for a potential fusion surgery reported kinesiophobia [20]. Even though the prevalence of kinesiophobia among patients with DDD is unknown, research suggests that the prevalence of kinesiophobia in patients with specific CLBP is similar to that in patients with non-specific CLBP [21]. Furthermore, pre-surgical psychological status such as pain catastrophizing [22], negative outcome expectations [23] and fear-avoidance beliefs [24] have been found to be significant predictors of pain and function up to 2 years after lumbar surgery. Hence, we hypothesise that the majority of persons who are waiting 
to undergo surgery for DDD suffers from a high degree of pain, kinesiophobia, catastrophizing and low self-efficacy and all of these factors may contribute to a low physical activity level. Hence, an intervention using a cognitive behavioural approach could be appropriate to target these risk factors. Given the multidimensional nature of pain, rehabilitation programs based on cognitive-behavioural therapies (CBT) have been specifically recommended for patients with CLBP and are often used in addition to other therapies such as exercise [25].

Although the importance of post-lumbar surgery rehabilitation programs targeting the above-mentioned psychological factors have been emphasised [26-28], so far only two programs have yielded successful outcomes following lumbar fusion surgery [28, 29]. Abbott et al. compared postoperative psychomotor therapy with exercise therapy in a randomised controlled trial (RCT) that included 107 patients undergoing lumbar fusion surgery for spinal stenosis, spondylosis, degenerative/isthmic spondylolisthesis or DDD. The psychomotor therapy program combined motor control exercises for lumbopelvic stabilisation with a cognitive behavioural intervention immediately after surgery. This treatment was more effective compared to exercise therapy in reducing disability and fear-avoidance beliefs and in increasing self-efficacy and outcome expectancy at 2 and 3 years post-surgery [28]. Another recent RCT compared a rehabilitation program including active exercise alone with a treatment combining active exercise with the management of catastrophizing and fear of movement among 130 patients undergoing lumbar fusion surgery for degenerative spondylolisthesis and/or lumbar spinal stenosis. The combined rehabilitation program showed superior disability reduction measured by the Oswestry Disability Index (ODI) at the 1-year follow-up [29].

These prior investigations have been performed after lumbar fusion surgery. However, some authors hypothesise that further optimisation of lumbar fusion surgery outcomes may be possible by initiating an intervention before surgery $[26,30]$. Nielsen et al. found their intervention to be superior to conventional care with regards to postoperative functionality assessed by the Roland-Morris Disability Questionnaire, faster recovery and shorter hospital stay. The content of the intervention was an individualised preoperative training program that focused on improvement of muscular back strength as well as cardiovascular conditioning before spinal fusion surgery [26].

To our knowledge, at the start of our trial (2014), no prior study had assessed the use of a prehabilitation program with individual sessions to target psychological risk factors - such as fear-avoidance beliefs and low selfefficacy - to maintain or increase physical activity both before and after surgery. Therefore, we initiated an RCT to evaluate a physiotherapeutic prehabilitation program called PREPARE (Prehabilitation, Physical Activity and exeRcisE).

\section{Aim of the study}

The overall aim of the trial is to investigate whether PREPARE - a physiotherapeutic prehabilitation program based on a cognitive behavioural approach - will improve functioning after lumbar fusion surgery in patients with DDD compared to conventional care.

\section{Hypotheses}

1. Patients who receive PREPARE - a physiotherapeutic person-centred prehabilitation program based on a cognitive behavioural approach - before spinal fusion surgery will experience decreased disability levels, improved functioning, increased physical activity level, better health-related quality of life, decreased leg and back pain intensity, less pain catastrophizing, less pain-related fear, increased self-efficacy to exercise and less depressed mood after surgery compared to patients who receive conventional care. We further hypothesise that the between-groups difference will be largest at 6 months after surgery.

2. Compared to those in the control group, patients who receive PREPARE will show a more rapid increase in their physical activity level measured objectively with an accelerometer at 3 and 6 months after surgery.

3. From a societal perspective, PREPARE will be more cost-effective and show higher cost-utilities compared to conventional care at one year after surgery.

\section{Methods/Design}

\section{Trial design}

A prospective RCT will be performed at a private spine clinic in Gothenburg, Sweden. Participants will be randomised to one of the two arms of the trial.

\section{Theoretical Framework}

The PREPARE program combines different philosophical standpoints, theoretical models and treatment principles.

Pain is defined as "an unpleasant and emotional experience associated with actual or potential tissue damage, or described in terms of such damage" [31], and is hence to be considered a subjective phenomenon. As PREPARE rests on the assumption that pain is subjective, we will apply the principles of person-centred care (PCC). In PCC, emphasis is placed on recognising the patient as a human being with reason, will, feelings, and need, and on engaging the patient as an active partner in his/her care and treatment [32]. The most important parts in PCC is the partnership between the patient and the therapist and to formulate a health plan together 
with the patient which includes both short-and long-term goals along with the actions needed to reach each goal.

Modern pain research has led to a shift in treatment strategies, from pain reduction to pain management with a focus on teaching patients to manage their thoughts (cognitive component) and feelings (affective component), which are both pain-related components. PREPARE will target fear-avoidance beliefs, as well as self-efficacy, which are regarded as important for a person's ability to stay active despite pain [33]. For patients of working age with LBP, evidence suggests that treatment should include cognitive behavioural techniques combined with physical activity [34]. Self-efficacy is a concept that explains a person's confidence in their ability to perform a specific activity [35]. In patients with LBP, both self-efficacy and fear-avoidance beliefs are possible predictors of disability $[33,36]$. However, since it remains unclear how these two constructs differ in predicting disability, it is suggested that therapists measure and consider both constructs when treating patients with LBP $[36,37]$. To achieve this, the physiotherapist will use a combination of techniques based on a cognitive behavioural approach [38]. Figure 1 presents an overview of the fear-avoidance model including the mediating role of self-efficacy.

\section{Participants}

We will recruit a total of 110 patients of $18-70$ years of age, who have major complaints of DDD: CLBP of motion-elicited type degenerative changes of 1-3 segments of the lumbar spine, reproducible pain in clinical examination assessed to originate in the same segment as demonstrating degenerative changes, and on the waiting list for lumbar fusion surgery. Patients may have additional minor radiating symptoms with or without simultaneous surgical procedure for disc herniation, foraminal decompression, or isthmic spondylolisthesis. The trial will exclude patients who have undergone previous decompression surgery for spinal stenosis or who have spinal malignancy, dominating radiculopathy, a confirmed neurological disorder or rheumatic disorder, deformities in the thoracolumbar spine (e.g. idiopathic scoliosis), or a poor understanding of the Swedish language.

\section{Recruitment and randomization}

Trial participants will be recruited from two private spine clinics and one university hospital. Patients will be clinically examined by an orthopaedic surgeon, who will make a medical diagnosis based on the clinical and radiological findings. Patients who are diagnosed with DDD will be informed that lumbar fusion surgery is a treatment option. When a patient agrees to undergo surgery and is placed on the waiting list, the hospital and the spine clinics coordinators will inform the physiotherapist (PT-prepare) who will deliver the trial intervention. Then the PT-prepare will call the patient to inform him/her of the trial and invite him/her to participate.

Patients interested in participating will meet with an independent observer at baseline, 8-12 weeks before surgery at one of the private spine clinics. The independent observer will once again provide the patient with information about the trial. If the patient agrees to participate, he/she will sign an informed consent form provided by the independent observer. The independent observer will then guide the participant through the functional capacity testing and provide him/her with the patient-reported outcome measures and the accelerometer. After this, the independent observer will give the participant a sealed envelope containing the group allocation.

The participant will be randomly allocated to Group A or Group B using a computerised random list with no restrictions, arranged by an independent statistician. The project leader - who will not take part in the intervention and outcome assessments - will be responsible for arranging sequentially numbered, opaque, sealed envelopes. To

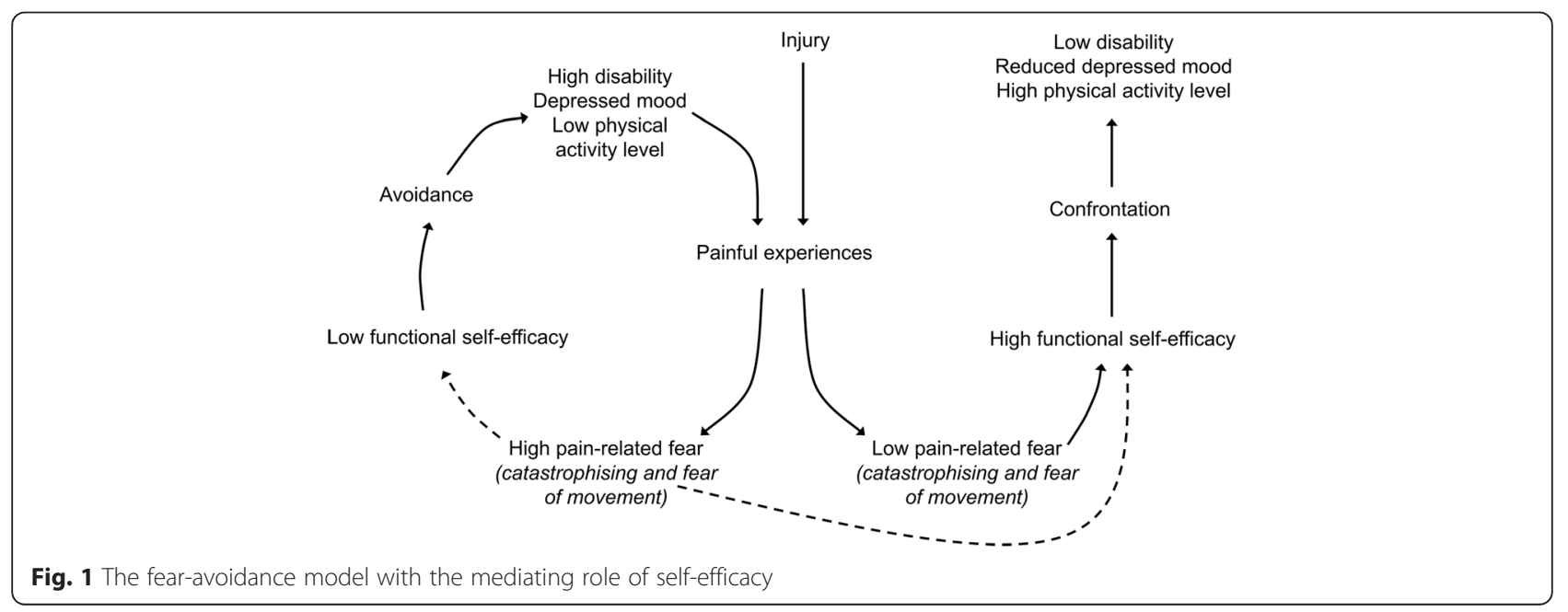


conceal the group allocation, the participant will not open this envelope in the presence of the independent observer. The allocation list will be stored in a locked fire-proof cupboard at the university laboratory, in accordance with the principles of the ethical approval.

\section{Blinding}

The independent observer who is responsible for all measurements will be blinded to the treatment allocation. The trial participants will be aware of the treatment that they receive, but will not know the content of the treatment in the control group. The PT-Prepare will not be blinded since she is delivering the treatment for Group A.

\section{Intervention}

Group A $(n=55)$ will be treated using the PREPARE protocol. Group B $(n=55)$ will receive conventional care, including general advice to stay active before surgery. Figure 2 presents an overview of the intervention groups.

\section{Group A}

The PREPARE protocol includes four individually tailored treatment sessions before surgery, and one booster session over the telephone two weeks after surgery. Depending on the patient's schedule, PREPARE typically starts about 8 to 12 weeks before surgery. Each treatment session lasts for about one hour, and the post-surgery booster session lasts about $30 \mathrm{~min}$. The intervention will be delivered by a physiotherapist with 1.5 years of CBT training. Figure 3 presents a schematic overview of the intervention.

Session 1 - Person-centred analysis of functioning The aim of session 1 is to perform an analysis to identify the patient's ability to stay active despite pain.

- Cognitive interview with a Socratic approach The patient participates in a cognitive interview aimed at capturing the patient's cognitions and feelings relating to staying active despite pain. To direct the interview's focus towards functioning rather than pain, the PT-prepare will discuss with the patient what kinds of physical activities he/she wishes to be able to perform after surgery.

- Modified PHODA - analysis of activity behaviour To capture the patient's cognitions and feelings regarding activity behaviours related to physical activities and the underlying motives of these behaviours, a modified version of the Photograph Series of Daily Activities (PHODA) will be used (described below) [39], which is extended to include additional photographs of leisure-based physical activities.

\section{- Homework}

Homework will be assigned with a two-fold aim: to help the patient learn to be aware of cognitions, feelings, behaviour, and body sensations related to a physical activity; and to increase or maintain his/her physical activity level. The patient will first make a list of physical activities that he/she would like to do, but has stopped performing or has been performing less often or less intensely due to his/her back problem. The patient will then select one of these physical activities, and monitor his/her cognitions, feelings, behaviours, and body sensations related to that physical activity as homework until session 2 .

- Identifying psychological risk factors

Questionnaires will be used to identify psychological risk factors for low functioning. Before session 2, the patient will complete the following questionnaires: Pain Catastrophizing Scale, Tampa Scale for Kinesiophobia and Self-efficacy for Exercise (described below).

Session 2 - Educational session The aim of session 2 is to increase the patient's knowledge regarding pain and the association between activity-related behaviours and underlying motives for these behaviours and form an individualised health plan.

- Follow-up of homework

The session will start with a discussion of the patient's cognitions, feelings, behaviours and body sensations related to the physical activity that he/she has monitored as homework.

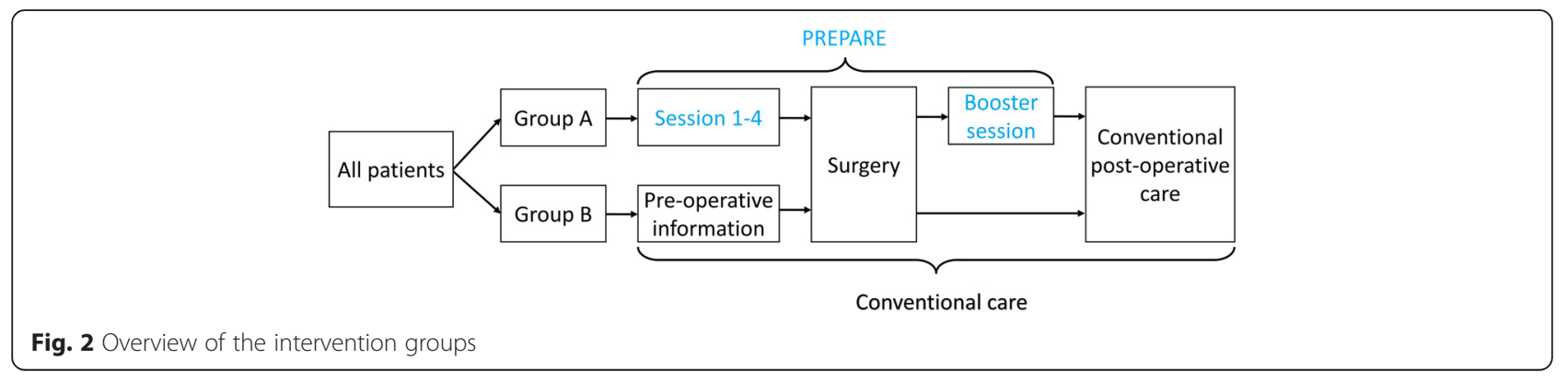




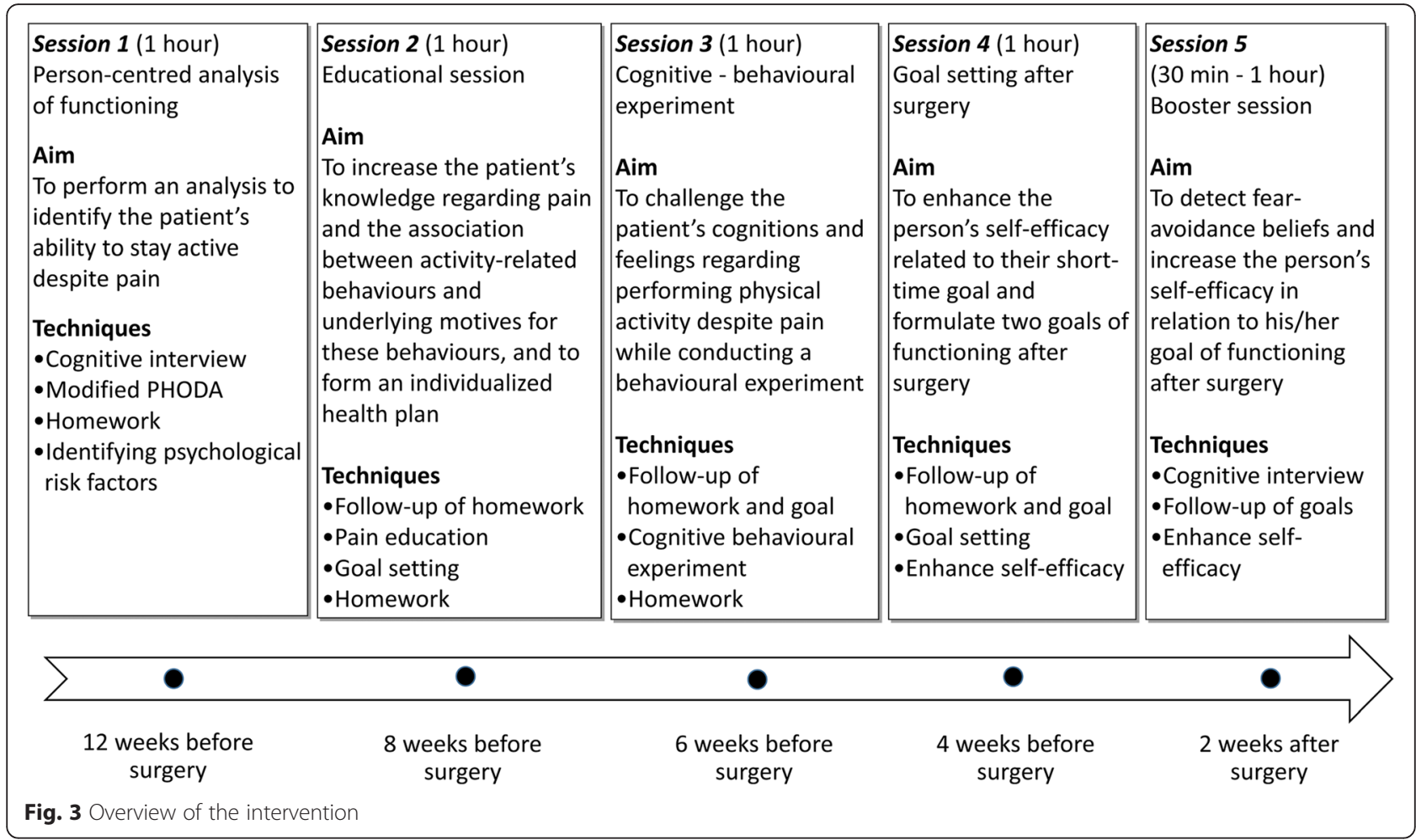

\section{- Pain education}

The patient will participate in an educational session about acute and chronic pain [40]. The theoretical underlying model for this pain education is the fear avoidance model presented by Vlaeyen et al. [19] and modified by Woby et al. [33]. The pain education session will be conducted as a dialogue between the PT-prepare and the patient, with the PT-prepare considering the patient's thoughts, beliefs and knowledge as well as what he/she wants to know about staying active despite pain in relation to his/her pain condition. The session will be guided by the patient's responses to the questionnaires completed after session 1, as well as the information from the patient's homework assignment. This will help the PT-prepare to form a health plan together with the patient and decide upon a person-centred goal in relation to the underlying theoretical models of the intervention.

- Goal setting - short-term goal

The patient will choose a person-centred short-term goal related to functioning that he/she will aspire to achieve before surgery. This short-term goal should be specific, measurable, achievable, realistic and time-targeted (SMART-goal) [41] and should involve a physical activity that is important to the patient. For example, a short-term goal could be to "go for a walk in the nearby forest for 30 min every day". The patient will be encouraged to work towards the goal in gradual steps to enhance his/her self-efficacy related to that physical activity.

- Homework

The homework assignment will have a three-fold aim: for the patient to learn to be aware of cognitions, feelings, behaviours and body sensations related to a physical activity; for the patient to increase his/her physical activity level, and finally to help the patient reach his/her short-time goal before surgery. The patient will choose this physical activity from the list of physical activities that he/she established during session 1.

Session 3 - Cognitive behavioural experiment The aim of session 3 is to challenge the patient's cognitions and feelings regarding performing physical activity despite pain while conducting a behavioural experiment.

- Follow-up of homework and short-term goal This session will start with a discussion of the patient's progress towards their short-term goal, as well as their cognitions, feelings and behaviours related to the physical activity that he/she has performed as homework.

- Cognitive behavioural experiment Under the supervision of the PT-Prepare, the patient will perform a behavioural experiment aiming to enhance inhibitory learning by testing and violating negative expectations that the patient might have 
regarding a physical activity. For the behavioural experiment in this session, the patient will select one physical activity from the list of physical activities established during session 1. Before the behavioural experiment, the patient will be asked about what cognitions he/she has about the activity and what he/she expects will happen when performing that physical activity. After performing the physical activity, the validity of the patient's thoughts and the patient's level of self-efficacy will be discussed in terms of both short- and long-term consequences.

\section{- Homework}

The three aims of the homework will be for the patient to learn to be aware of cognitions, feelings, behaviours and body sensations related to a physical activity, to increase his/her physical activity level, and to help the patient reach his/her short-term goal before surgery. The homework will be either the same physical activity selected during session 2 , or a new physical activity from the list of physical activities established during session 1.

Session 4 - Goal setting after surgery The aim of session 4 is to enhance the patient's self-efficacy related to their short-term goal and to formulate two functioningrelated goals to be reached at 4 and 8 weeks after surgery.

- Follow-up of homework and short-term goal This session will start with a discussion of the patient's progress of his/her short-term goal and of the patient's cognitions, feelings and behaviours related to the physical activity that he/she has performed as homework.

- Goal setting - 4 and 8 weeks after surgery The patient will choose two functioning related goals to reach at 4 and 8 weeks after surgery, which should involve a physical activity that is important to the patient. These goals will be set as SMART-goals [41].

- Enhance self-efficacy related to short-time goal The patient will be encouraged to continue working towards his/her short-term goal, and will be advised to take gradual steps towards enhancing his/her self-efficacy related to that goal. If the patient has already reached the short-term goal, the goal will be modified by increasing the intensity, duration, or frequency of the physical activity or by choosing another physical activity that the patient considers to be important.

Session 5 - Booster session The aim of session 5 is to detect fear-avoidance beliefs and to increase the patient's self-efficacy in relation to his functioning goals for 4 and 8 weeks after surgery. This session acts as a booster session that will be held over the phone at two weeks after surgery.

- Cognitive interview with a Socratic approach The patient will participate in a cognitive interview that aims to capture his/her cognitions and feelings regarding physical activities - particularly activities of daily life (ADL). The PT-prepare will identify tendencies towards fear-avoidance beliefs and encourage the patient to stay active.

- Follow-up of goals 4 and 8 weeks after surgery The patient's goals will be discussed and will be adjusted with regards to duration, intensity, or frequency in accordance with the patient's current medical status.

- Enhance self-efficacy related to goals 4 and 8 weeks after surgery

The patient will be encouraged to continue with his/her progress towards the goals, and will be advised to take gradual steps towards enhancing his self-efficacy related to that physical activity.

\section{Group B}

Patients in Group B will receive a conventional care intervention. Before surgery, these patients will be encouraged to contact a physiotherapist at one of the private spine clinics to schedule an informational session. There, they will be provided with basic information about the upcoming surgery, and told about the types of core exercises that will be introduced at the ward postsurgery. The physiotherapist will encourage the patients to stay active and to start performing the recommended exercises prior to their surgery.

\section{Common features for Group A and B after surgery}

The aim of this trial is to evaluate the effects of PREPARE rather than the postoperative treatment of the patients in Group A. Both groups will receive the same post-surgical treatment, aside from the booster session for Group A. After surgery, the patients will meet with a physiotherapist at the ward, and participants in both groups will receive the same information regarding postoperative rehabilitation. At the ward, both groups will be instructed to perform the same home exercise program comprising core stabilisation exercises for the first four weeks after surgery. All patients will be advised to stay active on a daily basis, and to contact a physiotherapist from a rehabilitation centre or physiotherapy clinic in their local area at four weeks after the surgery to continue their rehabilitation. The content of this rehabilitation will be determined by the treating physiotherapist and will not be controlled for. 


\section{Outcome measures}

\section{Primary outcome measure}

- Disability will be measured using the revised version (version 2.0) of the Oswestry Disability Index (ODI). In the ODI, patients rate their perceived disability on 10 items relating to pain intensity, personal care, lifting, walking, sitting, standing, sleeping, sex life, social life and traveling Each item is scored from $0-5$, with 0 indicating the least amount of disability and 5 the most severe disability. The scores are summed to generate a total score ranging from 0 to 100, with 0 indicating no disability. The English version of the ODI shows high internal consistency [42] and test-retest reliability [43], as well as adequate content validity and responsiveness [44] for patients with CLBP.

\section{Secondary outcome measures (effect evaluation)}

- Patient-reported functioning will be measured using the Swedish version of the Patient-Specific Functional Scale (PSFS). In the PSFS, the patient lists three activities that are limited by the condition for which he/she is seeking treatment. The patient then rates their perceived difficulty in performing each of the listed activities on a scale from 0 to 10 , with 0 indicating that the patient cannot perform the activity at all. The three separate scores are averaged to generate the total score The English version of the PSFS is responsive to clinically important change over time [45], and shows good test-retest reliability and strong criterion validity [46] for patients with CLBP.

- Performance-based functioning will be measured using five tests: 5-min walking (measurement of the distance the patient can walk in $5 \mathrm{~min}$ ); 50 -feet fast walking (measurement of the time it takes for a patient to walk 50 feet as fast as possible); the Timed up-and-go (measurement of the time it takes for a patient to arise from a chair, walk three meters, turn around, walk back to the chair and sit down); 1-min stair-climbing (measurement of the number of steps the patient can climb in one minute) [47, 48]; and the One-Leg Stand Test (measurement of the duration the patient can stand on one leg, with eyes open and with eyes closed) [49]. Findings support the construct validity of these tests and show that they have adequate test-retest reliability for patients with CLBP [47-49].

- A digital triaxial accelerometer (ActiGraph GT3X+; ActiGraph, Pensacola, FL, USA) will be used to assess physical activity as steps per day, time spent at different intensity levels and time spent sedentary $[50,51]$. The GT3X+ measures acceleration in three planes and the raw output is "counts". Based on the number of counts per minute, the raw output is classified into time spent at different intensities of physical activity and time spent sedentary by using appropriate cut-points in the complementary software, Actilife 6 (ActiGraph, Pensacola, FL, USA). The device will be attached with an elastic band to the patient's right iliac crests during waking hours for a 7-day period. The patient will be instructed to remove the device while sleeping, swimming and bathing. The GT3X+ has shown high construct validity when measuring physical activity intensity levels [50] and excellent criterion validity when measuring the number of steps [51] in healthy adults.

- Health-related quality of life will be measured using the Swedish version of the European Quality of Life 5 Dimensions Questionnaire (EQ-5D). In the EQ-5D, patients rate their health on five items relating to mobility, self-care, usual activities, pain/discomfort and anxiety/depression. The patient also rates his/her general health on a visual analogue scale. The English version of the EQ-5D has acceptable test-retest reliability and findings support its construct validity for patients with chronic musculoskeletal pain [52].

- Health-related quality of life will also be measured using the Swedish version of the Short Form (36) Health Survey (SF-36). The SF-36 comprises eight scaled sections: vitality, physical functioning, bodily pain, general health perceptions, physical role functioning, emotional role functioning, social role functioning and mental health [53]. The Swedish version of the SF-36 shows high internal consistency and high discriminant validity and findings support its construct validity in a Swedish population sample [54].

- Back and leg pain intensity levels over the last week will be measured using 100-mm Visual Analogue Scales (VAS) [55]. Findings support the validity and reliability of the VAS in patients with chronic pain [56].

- Pain will also be measured using a 5-point scale with the following response options: pain-free, much better, better, unchanged, or worse. This scale shows good responsiveness for patients with CLBP undergoing lumbar fusion surgery [57].

- Pain catastrophizing will be measured using the Swedish version of the Pain Catastrophizing Scale (PCS), which includes 13 items assessing catastrophizing thoughts about pain. The PCS has shown adequate internal consistency and high construct validity in a Swedish population sample [58].

- Kinesiophobia will be subjectively rated using the Swedish version of the Tampa Scale of Kinesiophobia (TSK-SV). The TSK comprises 17 items assessing the subjective kinesiophobia rating. The TSK-SV has 
shown high test-retest reliability and internal consistency, and has support for its face, content and construct validity in patients with CLBP [59].

- Self-efficacy related to exercise will be measured using the Swedish version of the Self-Efficacy for Exercise scale (SEE-SV). On the SEE-SV, the patient rates his/her confidence that he/she could exercise three times per week (20 min each session) under nine different conditions - for example, "if you experienced pain while you exercised" or "if you felt tired". The SEE-SV shows substantial test-retest reliability and satisfactory internal consistency and content validity for older adults [60].

- Anxiety and depression will be assessed using the Swedish version of the Hospital Anxiety and Depression Scale (HADS) [61]. In a Swedish population sample, the HADS showed moderate internal consistency and high construct validity [62].

- Satisfaction with treatment results will be measured using a 3-point scale with the following response options: satisfied, uncertain, or dissatisfied.

- PHODA is an instrument that is conventionally used to determine the perceived harmfulness of daily activities in patients with LBP [39]. In this trial, we will use a modified version of PHODA to capture the patients' beliefs and attitudes regarding activity behaviour, rather than the expected harmfulness. The original PHODA is extended with photos of leisure-based activities that the patient is also asked to rate in the above-described manner. The modified PHODA will not be used to measure outcomes of the present trial, but will rather be employed as a tool to supply the PT-prepare with information about the patient's activity behaviour in relation to the pictured physical activities and the motives underlying the activity behaviour.

\section{Secondary outcome measures (economic evaluation)}

- Healthcare costs and to value production loss will be measured using a self-reported custom-made health economic questionnaire.

\section{Data collection}

Data collection for the patient-reported outcome measures will take place at baseline (8-12 weeks before surgery), at 1 week before surgery; and at 3 weeks, 8 weeks, 3 months, 6 months, 1 year, 2 years and 5 years after surgery. Each participant will have a special numeric code, and all data will be stored in a fireproof cupboard and on a password-protected computer at one of the spine clinics. Double data entry and missing data in the questionnaires will be checked as soon as the participant has done the follow-up by an independent trial coordinator. Figure 4 presents details of the follow-up sessions.

\section{Analyses \\ Sample size}

The number of participants $(n=110)$ was determined based on a power analysis (80\% power, alpha $=0.05)$, with disability measured with ODI as the primary outcome. We determined that we required a sample size of 55 patients in each group to show a statistically significant between-group difference of at least 8 points in the ODI with a standard deviation of 15 based on earlier studies $[57,63]$. The difference of 8 points on the ODI was based on the previously reported minimal clinically important difference within the range of 5.2-16.3 where 10 points are mostly used for the ODI in a similar population $[57,64]$.

\section{Effect evaluation}

We will use an "intention to treat" approach to compare the effects of the different therapy conditions on both primary and all secondary outcomes. Data analysis will be performed using the statistics software SPSS 22 (IBM Corporation, New York, NY) for ODI at 6 months and all secondary outcomes at 6 months. The intervention group will be tested against the control group using two-sample $t$-test and Wilcoxon rank sum test depending on the data level of the outcomes. Interrelationship among the variables will be analysed using a multiple regression model with the ODI as outcome and the secondary outcomes as explanatory variables. In addition, possible mediations and interactions will be investigated. Since this trial will include repeated measures at different time-points, we will use a linear mixed model with random intercept [65].

To test the physical activity level between the groups at 3 and 6 months, we will use a two-sample $t$-test.

\section{Health economics}

For our health economic analysis, a societal viewpoint will be used. Indirect and direct healthcare costs will be measured using a self-reported custom-made health economic questionnaire. Days of hospital stay will be determined from patient charts. Intervention costs will be calculated for each patient - including the number and duration of treatments for the 55 patients who will receive PREPARE. We will compare the mean total costs between the therapy groups. The cost prices of medical consumption will be calculated. All costs will be presented in euros. The human capital approach will be used to calculate productivity costs.

We will use these data to perform a cost-effectiveness analysis and cost-utility analysis. For the cost-effectiveness analysis, an incremental cost-effectiveness ratio (ICER) 


\begin{tabular}{|c|c|c|c|}
\hline $\begin{array}{l}\text { BASELINE } \\
\text { Primary: } \\
\text { Disability (ODI) } \\
\text { Secondary: } \\
\text { - Patient-reported } \\
\text { functioning (PSFS) } \\
\text { - Performance-based } \\
\text { functioning (Timed up } \\
\text { and-go, 5-minute walk, 50 } \\
\text { foot walk, 1-minute stair } \\
\text { climbing, One-leg stand) } \\
\text { - Physical activity } \\
\text { (GT3X+ accelerometer) } \\
\text { - Health-related QoL } \\
\text { (EQ5D) } \\
\text { - Back and leg pain intensity } \\
\text { (VAS) } \\
\text { - Pain catastrophizing (PCS) } \\
\text { - Kinesiophobia (TSK) } \\
\text { - Self-efficacy related to } \\
\text { exercise (SES-SV) } \\
\text { - Anxiety (HADS) } \\
\text { - Depression (HADS) } \\
\text { - Health economic factors } \\
\text { (custom-made } \\
\text { questionnaire) }\end{array}$ & $\begin{array}{l}\text { PRE-SURGERY } \\
\text { Primary: } \\
\text { Disability (ODI) } \\
\text { Secondary: } \\
\text { - Patient-reported } \\
\text { functioning (PSFS) } \\
\text { - Health-related QoL } \\
\text { (EQ5D, SF-36) } \\
\text { - Pain catastrophizing (PCS) } \\
\text { - Kinesiophobia (TSK) } \\
\text { - Self-efficacy related to } \\
\text { exercise (SES-SV) } \\
\text { - Anxiety (HADS) } \\
\text { - Depression(HADS) } \\
\text { - Back and leg pain } \\
\text { intensity (VAS) } \\
\text { - Health economic factors } \\
\text { (custom-made } \\
\text { questionnaire) }\end{array}$ & $\begin{array}{l}\text { FOLLOW-UP 1-2 } \\
\text { Primary: } \\
\text { Disability (ODI) } \\
\text { Secondary: } \\
\text { - Patient-reported } \\
\text { functioning (PSFS) } \\
\text { - Health-related QoL } \\
\text { (EQ5D) } \\
\text { - Pain catastrophizing (PCS) } \\
\text { - Kinesiophobia (TSK) } \\
\text { - Self-efficacy related to } \\
\text { exercise (SES-SV) } \\
\text { - Anxiety (HADS) } \\
\text { - Depression (HADS) } \\
\text { - Leg and back pain } \\
\text { intensity (VAS) } \\
\text { - Health economic factors } \\
\text { (custom-made } \\
\text { questionnaire) }\end{array}$ & $\begin{array}{l}\text { FOLLOW-UP 3-7 } \\
\text { Primary: } \\
\text { Disability (ODI) } \\
\text { Secondary: } \\
\text { - Patient-reported } \\
\text { functioning (PSFS) } \\
\text { - Performance-based } \\
\text { functioning (Timed up } \\
\text { and-go, 5-minute walk, 50 } \\
\text { foot walk, 1-minute stair } \\
\text { climbing, One-leg stand) } \\
\text { - Physical activity } \\
\text { (GT3X+ accelerometer) } \\
\text { - Health-related QoL } \\
\text { (EQ5D, SF-36) } \\
\text { - Back and leg pain intensity } \\
\text { (VAS) } \\
\text { - Pain catastrophizing (PCS) } \\
\text { - Kinesiophobia (TSK) } \\
\text { - Self-efficacy related to } \\
\text { exercise (SES-SV) } \\
\text { - Anxiety (HADS) } \\
\text { - Depression (HADS) } \\
\text { - Satisfaction with treatment } \\
\text { results (3-point scale) } \\
\text { - Health economic factors } \\
\text { (custom-made } \\
\text { questionnaire) }\end{array}$ \\
\hline
\end{tabular}

Fig. 4 Overview of the baseline and follow-up sessions. EQ-5D, EuroQol 5 Dimensions Questionnaire; HADS, Hospital Anxiety and Depression Scale; ODI, Oswestry Disability Index 2.0; PCS, Pain Catastrophizing Scale; PSFS, Patient-Specific Functional Scale; QoL, quality of life; SES-SV, Self-efficacy Scale for Exercise; TSK, Tampa Scale for Kinesiophobia; SF-36, Short Form (36) Health Survey; VAS, Visual Analogue Scale of Pain

will be calculated, weighing total costs against disability levels (ODI). For the cost-utility analysis, utility will be calculated from EQ-5D scores for every assessment. Mean total costs will be weighed against mean health utility, i.e. comparing cost per Quality Adjusted Life Years (QALY) gained.

\section{Discussion}

The overall aim of our trial is to investigate whether patients experience improved post-operative functioning if they receive a pre-surgical physiotherapeutic prehabilitation program based on a cognitive behavioural approach, as compared to conventional care.

As stated previously, at the time that the present trial was designed, no prior investigation had examined a prehabilitation program with a cognitive behavioural approach. To this date, two studies have been published within the field $[26,30]$. We would like to clarify the similarities and differences in order to argue for the added value of our planned trial, PREPARE. All three of the studies were set up with RCT designs, and disability was one of the primary outcomes [26]. Disability is however measured somewhat differently in the various studies. Nielsen et al. used the term functionality, which was assessed by the Roland Morris Disability Questionnaire and two performance-based outcome measures (the Sitto-stand test and the Timed-up-and-go test) [26]. Rolving et al. used the ODI as the primary patient-reported outcome measure but did not use any performance-based outcome measures of functioning [30]. In PREPARE we use a combination of outcome measures (patient-reported and performance-based outcome measures as well as accelerometer data). We would argue that this will provide a more comprehensive picture of the patient's functioning as reflected in the International Classification of Functioning, Disability and Health [66].

The intervention programs in the three studies mentioned above vary somewhat in the underlying theoretical models and content. PREPARE is being performed from a person-centred perspective [32]. In concrete terms, it means that we have set up person-centred treatment sessions on a one-to-one basis. This is in line with the trial from Nielsen et al. in which the healthcare professional met the patient on an individual basis before surgery. In their intervention program, the patient met with the physiotherapist on two occasions, at the day of inclusion and two weeks before surgery [26]. In order to gradually challenge the patient's 
cognitive beliefs and to facilitate the patient's selfefficacy in relation to staying active despite pain, we have included four sessions and one booster session.

As argued for in the introduction section, the main principle of our prehabilitation program is to help the patients to stay active despite pain. Both Nielsen et al. and Rolving et al. seem to have built their prehabilitation program on the same principle. Nielsen et al. investigated the effect of an individualised preoperative training program that focused on improvement of muscular back strength as well as cardiovascular conditioning before surgery [26]. Rolving et al., on the other hand, had a stronger cognitive behavioural focus of their intervention program [30]. The relevance of the pre-surgical psychological status is an important determinant of surgical outcome in PREPARE. In accordance with the modified fear-avoidance model, we hypothesise that by trying to influence catastrophizing thoughts and patient's selfefficacy beliefs to exercise the patients in the intervention group will increase their level of functioning and physical activity level. In addition, in PREPARE we combine cognitive behavioural techniques with physical activity goal setting which we argue is a major strength that will further help the patients to be more active despite pain both before and after surgery.

\section{Trial status}

Participant recruitment started in April 2014 and is planned to continue until December 2016. It is expected that data regarding the intervention effects and the economic analyses will be available at the end of 2017.

\section{Acknowledgement}

Not applicable.

\section{Funding}

The trial was supported by The Eurospine Research Grants; The Swedish Research Council (VR); and The Health and Medical Care Executive Board of the Västra Götaland Region (VGR).

\section{Availability of data and materials}

No data has been collected yet. All methods/questionnaires have been described in the study protocol.

\section{Authors 'contributions}

$\mathrm{HL}$ and $\mathrm{ML}$ conceived the study, designed the study and the intervention, planned the evaluation and the coordination of the study and obtained ethical approval. $\mathrm{HL}$ was also responsible for delivering the intervention and drafted the manuscript. ML furthermore was responsible for funding the project and revision of the manuscript. MJ Participated in the coordination of the study, the analysis of the data from the physical capacity tasks and revised the manuscript. $\mathrm{HB}, \mathrm{AG}$ and $\mathrm{OH}$, provided expertise and participated in the design of the study and revised the manuscript critically. RS Participated in the design and planning of the study, the development of the intervention PREPARE, and revised the manuscript critically for important intellectual content. MDH Participated in the development and planning of the intervention PREPARE and revised the manuscript. LEO participated in the development of the intervention with aspect on person-centred care and revised the manuscript. All authors have critically read and approved the final version of the manuscript to be published.

\section{Authors' information}

This project is in every way the product of a good collaborative teamwork. The collaborators in this project are both academically well-educated and clinically highly experienced persons. Each one of them contributes to the project's quality in his/her own specific way.

Hanna Lotzke is an experienced PT with more than 20 years of clinical experience with patients with CLBP. She also holds and academic master degree within physical therapy, and she has $1 \frac{1}{2}$ years of CBT training. In this project, Hanna is the one who provides the active intervention.

Max Jakobsson is a PT with an ongoing PhD education. He has five years of experience in rehabilitation of patients with pain. His PhD project covers functioning and physical activity in patients with CLBP. Furthermore, Max is the project coordinator of the current study, and he coordinates all patients from baseline to follow-up.

Helena Brisby is an orthopaedic surgeon with more than 20 years of experience within surgery. Helena is also a professor of orthopaedics, and she has published extensively within the field of LBP. Her research ranges from basic science to applied clinical work. Professor Brisby has her own line of research in which she has received money from national and international funding in competition

Marlies den Hollander is a psychologist with expertise in behavioural medicine. She also has a background in occupational therapy. Marlies has worked for several years developing a successful behavioural treatment strategy for patients with persistent pain. Marlies role in this project has been to develop the intervention and to control for the quality of the intervention. Annelie Gutke is a full-time university lecturer with a PhD in medicine. She is working part-time as a clinician within primary health care. Dr Gutke is specialised in women's health. Dr Gutke is engaged in this project for her expertise in performance measures and for her experience on performing RCTs. Olle Hägg is an orthopaedic spine surgeon with more than 35 years of experience in surgery. His main interest in research is the treatment of patients with CLBP. He is one of the founders of the Swedish Society of Spinal Surgeons and of the Swedish Surgical Spine Register (Swespine), one of the first in the world.

Lars-Eric Olsson is a nurse and an associate professor. Dr Olsson has extensive experience of performing and teaching within person-centred care. Rob Smeets is a professor of rehabilitation medicine, and he is also working as a physiatrist with patients in pain. Professor Smeets has published over 110 articles, the majority within the field of pain. He has supervised 8 PhD students who have finished their PhD education, and he is currently involved in international collaborations worldwide. His role in the project is foremost his expertise on patients with pain who are fearful. Professor Smeets has set up several RCTs within the field of CLBP.

Mari Lundberg is a physical therapist and an associate professor at Karolinska Institutet. She has more than 10 years of clinical experience of patients with pain. She is also the project leader of this project. Moreover, she holds money from the Swedish Research Council, The Eurospine Research Grants and The AFA Insurance Funding for the project.

\section{Competing interests}

The authors declare that they have no competing interest.

\section{Consent for publication}

Not applicable.

\section{Ethics approval and consent to participate}

This trial has been approved by the Ethical Committee of Gothenburg, Dnr.586-11.

All patients that agree to participate will sign an informed consent form provided by the independent observer.

\section{Author details}

${ }^{1}$ Department of Orthopaedics, Institute of Clinical Science, Sahlgrenska Academy, University of Gothenburg, Gothenburg, Sweden. ${ }^{2}$ Spine Center Göteborg, Västra Frölunda, Sweden. ${ }^{3}$ District Department North, Division of Rehabilitation, Borås Stad, Borås, Sweden. ${ }^{4}$ Division of Physiotherapy, Department of Health and Rehabilitation, Institute of Neuroscience and Physiology, University of Gothenburg, Gothenburg, Sweden. ${ }^{5}$ Department of Rehabilitation Medicine, Maastricht University, Maastricht, The Netherlands. ${ }^{6}$ Libra Rehabilitation and Audiology, Eindhoven/Weert, The Netherlands.

${ }^{7}$ Department of Rehabilitation Medicine, Maastricht University, Medical 
Centre, Maastricht, The Netherlands. ${ }^{8}$ Department of Clinical Psychological Science, Maastricht University, Maastricht, The Netherlands. ${ }^{9}$ Division of Physiotherapy, Department of Neurobiology, Care Sciences and Sociology, Karolinska Institutet, Stockholm, Sweden. ${ }^{10}$ Department of Orthopaedics, Sahlgrenska University Hospital, Gothenburg, Sweden. ${ }^{11}$ Institute of Health and Care Sciences, Sahlgrenska Academy, University of Gothenburg, Gothenburg, Sweden. ${ }^{12}$ Gothenburg Centre for Person-Centred Care (GPCC), University of Gothenburg, Gothenburg, Sweden. ${ }^{13}$ Physiotherapy Department Spine Center AB, 43021 Västra Frölunda, Sweden.

\section{Received: 29 January 2016 Accepted: 4 August 2016} Published online: 18 August 2016

\section{References}

1. Livshits G, Popham M, Malkin I, Sambrook PN, Macgregor AJ, Spector T, et al. Lumbar disc degeneration and genetic factors are the main risk factors for low back pain in women: the UK Twin Spine Study. Ann Rheum Dis. 2011;70(10):1740-5. doi:10.1136/ard.2010.137836.

2. Harris IA, Dao ATT. Trends of spinal fusion surgery in Australia: 1997 to 2006. ANZ J Surg. 2009;79(11):783-8. doi:10.1111/j.1445-2197.2009.05095.x.

3. Strömqvist B, Fritzell P, Hagg O, Jonsson B, Sanden B. Swespine: the Swedish spine register: the 2012 report. Eur Spine J. 2013;22(4):953-74 doi:10.1007/s00586-013-2758-9.

4. Rajaee SS, Bae HW, Kanim LE, Delamarter RB. Spinal fusion in the United States: analysis of trends from 1998 to 2008. Spine (Phila Pa 1976). 2012; 37(1):67-76. doi:10.1097/BRS.0b013e31820cccfb.

5. Strömqvist B, Fritzell P, Hägg O, Knutsson B, Sandén B. SweSpine, The Swedish spine register - 2014 Report. Stockholm: Swedish Society of Spinal Surgeons; 2014.

6. Santa Mina D, Clarke H, Ritvo P, Leung YW, Matthew AG, Katz J, et al. Effect of total-body prehabilitation on postoperative outcomes: a systematic review and meta-analysis. Physiotherapy. 2014;100(3):196-207. doi:10.1016/j. physio.2013.08.008.

7. Spain J. Prehabilitation. Clin Sports Med. 1985;4(3):575-85.

8. Rushton A, Eveleigh G, Petherick EJ, Heneghan N, Bennett R, James G et al. Physiotherapy rehabilitation following lumbar spinal fusion: A systematic review and meta-analysis of randomised controlled trials. BMJ Open. 2012; 2(4). doi:10.1136/bmjopen-2012-000829.

9. Gilmore SJ, McClelland JA, Davidson M. Physiotherapeutic interventions before and after surgery for degenerative lumbar conditions: a systematic review. Physiotherapy. 2015;101(2):111-8. doi:10.1016/j.physio.2014.06.007.

10. Rushton A, Wright C, Heap A, White L, Eveleigh G, Heneghan N. Survey of current physiotherapy practice for patients undergoing lumbar spinal fusion in the United kingdom. Spine (Phila Pa 1976). 2014;39(23):E1380-7. doi:10.1097/brs.0000000000000573.

11. Koes BW, van Tulder M, Lin CW, Macedo LG, McAuley J, Maher C. An updated overview of clinical guidelines for the management of non-specific low back pain in primary care. Eur Spine J. 2010;19(12):2075-94. doi:10.1007/ s00586-010-1502-y.

12. Hills AP, Street SJ, Byrne NM. Physical Activity and Health: "What is Old is New Again". Adv Food Nutr Res. 2015;75:77-95. doi:10.1016/bs.afnr.2015.06.001.

13. World Health Organization. Global health risks - Mortality and burden of disease attributable to selected major risks. Geneva: World Health Organization; 2009.

14. Naugle KM, Fillingim RB, Riley 3rd JL. A meta-analytic review of the hypoalgesic effects of exercise. J Pain. 2012;13(12):1139-50. doi:10.1016/j. jpain.2012.09.006.

15. Nijs J, Kosek E, Van Oosterwijck J, Meeus M. Dysfunctional endogenous analgesia during exercise in patients with chronic pain: to exercise or not to exercise? Pain Physician. 2012;15(3 Suppl):Es205-13.

16. Hoffman MD, Shepanski MA, Mackenzie SP, Clifford PS. Experimentally induced pain perception is acutely reduced by aerobic exercise in people with chronic low back pain. J Rehabil Res Dev. 2005;42(2):183-90.

17. Meeus M, Roussel NA, Truijen S, Nijs J. Reduced pressure pain thresholds in response to exercise in chronic fatigue syndrome but not in chronic low back pain: an experimental study. J Rehabil Med. 2010;42(9):884-90. doi:10.2340/16501977-0595

18. Manigandan C, Charles J, Divya I, Edward SJ, Aaron A. Construction of exercise attitude questionnaire-18 to evaluate patients' attitudes toward exercises. Int J Rehabil Res. 2004;27(3):229-31.
19. Vlaeyen JW, Kole-Snijders AM, Boeren RG, van Eek H. Fear of movement/ (re)injury in chronic low back pain and its relation to behavioral performance. Pain. 1995;62(3):363-72.

20. Lundberg M. Kinesiophobia: various aspects of moving with musculoskeletal pain. Gothenburg: Department of Orthopaedics, Institute of Clinical Sciences, The Sahlgrenska Academy, University of Gothenburg; 2006.

21. Lundberg M, Frennered K, Hagg O, Styf J. The impact of fear-avoidance model variables on disability in patients with specific or nonspecific chronic low back pain. Spine (Phila Pa 1976). 2011;36(19):1547-53. doi:10.1097/BRS. Ob013e3181f61660.

22. Abbott AD, Hedlund R, Tyni-Lenné R. Patients' experience post-lumbar fusion regarding back problems, recovery and expectations in terms of the international classification of functioning, disability and health. Disabill Rehabil. 2011;33(15-16):1399-408.

23. Yee A, Adjei N, Do J, Ford M, Finkelstein J. Do patient expectations of spinal surgery relate to functional outcome? Clin Orthop Relat Res. 2008;466(5): 1154-61. doi:10.1007/s11999-008-0194-7.

24. Mannion AF, Elfering A, Staerkle R, Junge A, Grob D, Dvorak J, et al. Predictors of multidimensional outcome after spinal surgery. Eur Spine J. 2007;16(6):777-86. doi:10.1007/s00586-006-0255-0.

25. van Middelkoop M, Rubinstein SM, Kuijpers $T$, Verhagen AP, Ostelo R, Koes BW, et al. A systematic review on the effectiveness of physical and rehabilitation interventions for chronic non-specific low back pain. Eur Spine J. 2011;20(1):19-39. doi:10.1007/s00586-010-1518-3.

26. Nielsen PR, Jorgensen LD, Dahl B, Pedersen T, Tonnesen H. Prehabilitation and early rehabilitation after spinal surgery: randomized clinical trial. Clin Rehabil. 2010;24(2):137-48. doi:10.1177/0269215509347432.

27. Mannion AF, Brox JI, Fairbank JC. Comparison of spinal fusion and nonoperative treatment in patients with chronic low back pain: long-term follow-up of three randomized controlled trials. Spine J. 2013;13(11):1438-48. doi:10.1016/j.spinee.2013.06.101.

28. Abbott AD, Tyni-Lenne R, Hedlund R. Early rehabilitation targeting cognition, behavior, and motor function after lumbar fusion: a randomized controlled trial. Spine (Phila Pa 1976). 2010;35(8):848-57. doi:10.1097/BRS. Ob013e3181d1049f.

29. Monticone M, Ferrante S, Teli M, Rocca B, Foti C, Lovi A et al. Management of catastrophising and kinesiophobia improves rehabilitation after fusion for lumbar spondylolisthesis and stenosis. A randomised controlled trial. Eur Spine J. 2013. doi:10.1007/s00586-013-2889-z

30. Rolving N, Nielsen CV, Christensen FB, Holm R, Bunger CE, Oestergaard LG. Does a Preoperative Cognitive-behavioural Intervention affect disability, pain behaviour, pain and return to work the first year after Lumbar Spinal Fusion Surgery? Spine (Phila Pa 1976). 2015. doi:10.1097/brs.0000000000000843

31. Merskey H. Pain terms: a list with definitions and notes on usage. Recommended by the IASP Subcommittee on Taxonomy. Pain. 1979;6(3):249.

32. Ekman I, Swedberg K, Taft C, Lindseth A, Norberg A, Brink E, et al. Personcentered care-ready for prime time. Eur J Cardiovasc Nurs. 2011;10(4):248-51. doi:10.1016/j.ejcnurse.2011.06.008.

33. Woby SR, Urmston M, Watson PJ. Self-efficacy mediates the relation between pain-related fear and outcome in chronic low back pain patients. Eur J Pain. 2007;11(7):711-8. doi:10.1016/j.ejpain.2006.10.009.

34. Kamper SJ, Apeldoorn AT, Chiarotto A, Smeets RJ, Ostelo RW, Guzman J, et al. Multidisciplinary biopsychosocial rehabilitation for chronic low back pain. Cochrane Database Syst Rev. 2014;9:Cd000963. doi:10.1002/14651858. CD000963.pub3.

35. Bandura A. Self-efficacy: toward a unifying theory of behavioral change. Psychol Rev. 1977;84(2):191-215.

36. Ayre M, Tyson GA. The role of self-efficacy and fear-avoidance beliefs in the prediction of disability. Aust Psychol. 2001;36(3):250-3. doi:10.1080/ 00050060108259663.

37. Costa Lda C, Maher CG, McAuley JH, Hancock MJ, Smeets RJ. Self-efficacy is more important than fear of movement in mediating the relationship between pain and disability in chronic low back pain. Eur J Pain. 2011;15(2): 213-9. doi:10.1016/j.ejpain.2010.06.014.

38. Turk D, Okifuji A. A cognitive-behavioural approach to pain management. In: Wall PD, Melzack R, editors. Textbook of pain. 3rd ed. Edinburgh: Churchill Livingstone; 1993.

39. Leeuw M, Goossens ME, van Breukelen GJ, Boersma K, Vlaeyen JW. Measuring perceived harmfulness of physical activities in patients with chronic low back pain: the Photograph Series of Daily Activities-short electronic version. J Pain. 2007;8(11):840-9. doi:10.1016/j.jpain.2007.05.013. 
40. Moseley GL, Nicholas MK, Hodges PW. A randomized controlled trial of intensive neurophysiology education in chronic low back pain. Clin J Pain. 2004;20(5):324-30

41. Bovend'Eerdt TJ, Botell RE, Wade DT. Writing SMART rehabilitation goals and achieving goal attainment scaling: a practical guide. Clin Rehabil. 2009;23(4): 352-61. doi:10.1177/0269215508101741.

42. Fairbank JCT, Pynsent PB. The oswestry disability index. Spine (Phila Pa 1976). 2000;25(22):2940-53.

43. Davidson M, Keating JL. A Comparison of Five Low Back Disability Questionnaires: Reliability and Responsiveness. Phys Ther. 2002;82(1):8-24.

44. Smeets R, Koke A, Lin CW, Ferreira M, Demoulin C. Measures of function in low back pain/disorders: Low Back Pain Rating Scale (LBPRS), Oswestry Disability Index (ODI), Progressive Isoinertial Lifting Evaluation (PILE), Quebec Back Pain Disability Scale (QBPDS), and Roland-Morris Disability Questionnaire (RDQ). Arthritis Care Res. 2011;63 Suppl 11:S158-73. doi:10.1002/acr.20542.

45. Maughan EF, Lewis JS. Outcome measures in chronic low back pain. Eur Spine J. 2010;19(9):1484-94. doi:10.1007/s00586-010-1353-6.

46. Stratford P. Assessing Disability and Change on Individual Patients: A Report of a Patient Specific Measure. Physiother Can. 1995;47(4):258-63.

47. Simmonds MJ, Olson SL, Jones S, Hussein T, Lee CE, Novy D, et al. Psychometric characteristics and clinical usefulness of physical performance tests in patients with low back pain. Spine (Phila Pa 1976). 1998;23(22):2412-21.

48. Smeets RJEM, Hijdra HJM, Kester ADM, Hitters MWGC, Knottnerus JA. The usability of six physical performance tasks in a rehabilitation population with chronic low back pain. Clin Rehabil. 2006;20(11):989-98.

49. Maribo T, Iversen E, Andersen NT, Stengaard-Pedersen K, SchiottzChristensen B. Intra-observer and interobserver reliability of One Leg Stand Test as a measure of postural balance in low back pain patients. Int Musculoskelet Med. 2009;31:172-7.

50. Kelly L, McMillan D, Anderson A, Fippinger M, Fillerup G, Rider J. Validity of actigraphs uniaxial and triaxial accelerometers for assessment of physical activity in adults in laboratory conditions. BMC Med Phys. 2013;13(1):5.

51. Gatti AA, Stratford PW, Brenneman EC, Maly MR. GT3X+ accelerometer placement affects the reliability of step-counts measured during running and pedal-revolution counts measured during bicycling. J Sports Sci. 2015:1-8. doi:10.1080/02640414.2015.1096018

52. Conner-Spady BL, Marshall DA, Bohm E, Dunbar MJ, Loucks L, Khudairy AA et al. Reliability and validity of the EQ-5D-5L compared to the EQ-5D-3L in patients with osteoarthritis referred for hip and knee replacement. Qual Life Res. 2015. doi:10.1007/s11136-014-0910-6

53. Ware Jr JE, The SCD, MOS. 36-item short-form health survey (SF-36). I. Conceptual framework and item selection. Med Care. 1992;30(6):473-83.

54. Sullivan M, Karlsson J, Ware Jr JE. The Swedish SF-36 Health Survey-I. Evaluation of data quality, scaling assumptions, reliability and construct validity across general populations in Sweden. Soc Sci Med. 1995;41(10):1349-58.

55. Price DD, McGrath PA, Rafii A, Buckingham B. The validation of visual analogue scales as ratio scale measures for chronic and experimental pain. Pain. 1983;17(1):45-56.

56. Carlsson AM. Assessment of chronic pain. I. Aspects of the reliability and validity of the visual analogue scale. Pain. 1983;16(1):87-101.

57. Hagg O, Fritzell P, Oden A, Nordwall A. Simplifying outcome measurement: evaluation of instruments for measuring outcome after fusion surgery for chronic low back pain. Spine (Phila Pa 1976). 2002;27(11):1213-22.

58. Sullivan MJL, Bishop SR, Pivik J. The Pain Catastrophizing Scale: Development and validation. Psychol Assess. 1995;7(4):524-32.

59. Lundberg MKE, Styf J, Carlsson SG. A psychometric evaluation of the Tampa Scale for Kinesiophobia - From a physiotherapeutic perspective. Physiother Theory Pract. 2004;20(2):121-33.

60. Rydwik E, Hovmoller F, Bostrom C. Aspects of reliability and validity of the Swedish version of the Self-Efficacy for Exercise Scale for older people. Physiother Theory Pract. 2014;30(2):131-7. doi:10.3109/09593985.2013.838614.

61. Zigmond AS, Snaith RP. The Hospital Anxiety and Depression Scale. Acta Psychiatr Scand. 1983;67(6):361-70. doi:10.1111/j.1600-0447.1983.tb09716.x.

62. Lisspers J, Nygren A, Soderman E. Hospital Anxiety and Depression Scale (HAD): some psychometric data for a Swedish sample. Acta Psychiatr Scand. 1997;96(4):281-6.

63. Peacock J, Peacock PJ. Oxford handbook of medical statistics. Oxford: Oxford University Press; 2011.

64. Hägg O. Measurement and prediction of outcome: application in fusion surgery for chronic low back pain. Gothenburg: Department of
Orthopaedics, Institute of Clinical Sciences, The Sahlgrenska Academy, University of Gothenburg; 2002.

65. Twisk JWR. Applied longitudinal data analysis for epidemiology: a practical guide. Cambridge: Cambridge University Press; 2003.

66. World Health Organization. International Classification of Functioning, Disability and Health. Geneva: World Health Organization; 2001.

\section{Submit your next manuscript to BioMed Central and we will help you at every step:}

- We accept pre-submission inquiries

- Our selector tool helps you to find the most relevant journal

- We provide round the clock customer support

- Convenient online submission

- Thorough peer review

- Inclusion in PubMed and all major indexing services

- Maximum visibility for your research

Submit your manuscript at www.biomedcentral.com/submit

) Biomed Central 